\title{
The modelling and strength analysis of the endoprosthesis of the knee joint
}

\author{
Patrycja Kępa ${ }^{1}$, and Jakub Gajewski ${ }^{1, *}$ \\ ${ }^{1}$ Lublin University of Technology, Faculty of Mechanical Engineering, Department of Machine Design and Mechatronics, \\ Nadbystrzycka 36, 20-618, Lublin, Poland
}

\begin{abstract}
The knee joint is the largest of all in the human body. It connects the femur, tibia and patella. It is a double-angled joint reinforced with ligaments and surrounded by a joint capsule. Because of the bandy leg or knock-knee, cartilage wear due to age or defective joint load, alloplastic surgery is required. This is a procedure planned individually for each patient depending on their age, gender or weight. To assess the scale of wear, knee cartilage was scanned using computed tomography. CT scans were processed into a 3D model using Materialize Mimics. Based on obtained bone models, a model of the endoprosthesis was designed using the Catia V5 software. Strength analysis was carried out based on the selection of appropriate materials and theoretically accepted loads.
\end{abstract}

\section{Introduction}

The demand for knee arthroplasty is increasing. It is caused by obesity, degenerative disease or age. Active people are also affected by this problem due to the faster wear of cartilage. That is why the continuous development of this orthopaedic department is so important. Solutions proposed by engineers should combine bio features, innovation and satisfaction of doctors and patients.

\section{The anatomy of knee joint}

A knee joint is a double-angled joint or a hinge joint modified (Fig. 1). It consists of the femur, kneecap and tibia. Between the femur and tibia are the lateral and medial meniscus. These are natural knee joint fillers that provide stability, nourish cartilage, support shock absorption and load transfer. Knee joint is strengthened with internal and external ligaments. Internal ligaments are anterior cruciate ligament, posterior cruciate ligament and transverse ligament. External ligaments are medial and collateral ligaments, oblique fibre, arcuate popliteal ligament, kneecap ligament and strap. Bone ends are covered with facies atricularis, which provides elastic movement in the knee. The other elements of the knee joint are protected by a joint capsule syndrome consisting of fibrous and synovial membranes. The fibrous membrane consists mainly of collagen fibres. In contrast, the synovium produces a fluid that helps in bone adhesion relative to each other, reduces wear between surfaces joints and friction [1].

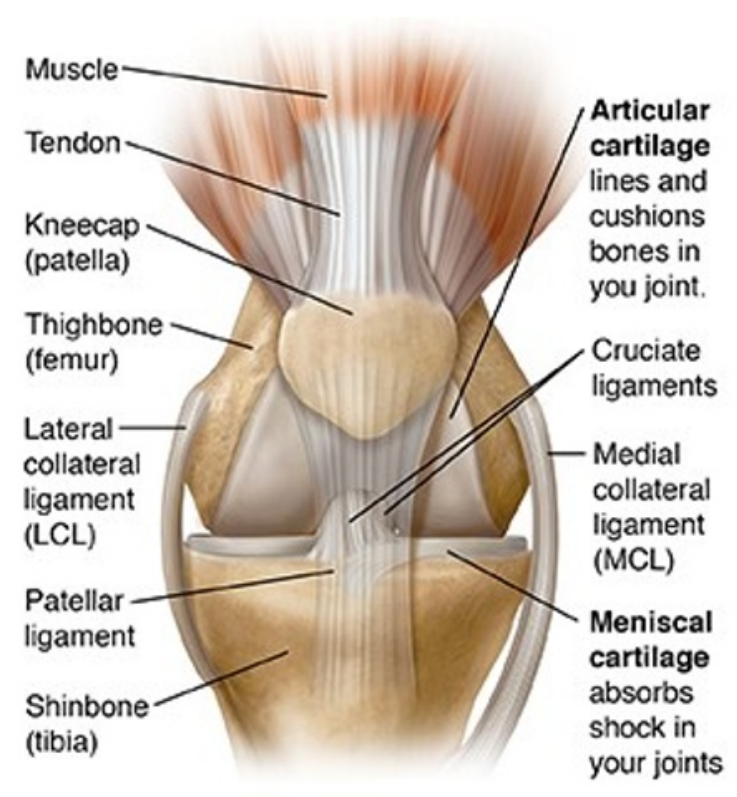

Fig. 1. Construction of the knee joint [2].

\section{Total knee arthroplasty}

Endoprosthesis is a procedure consisting of a deletion of damaged joint surfaces and replacing them with simulated parts. The endoprosthesis is selected on the basis of X-ray examinations, gender, age and weight of the patient. It is made of biomaterials, i.e. materials biomedicals that exhibit biocompatibility with human tissues. In the case when the elements of the endoprosthesis replace only partially the used joint, we talk about partial arthroplasty. And if they replace the distal part of the femur and the proximal part of the tibia bone together with the insert

\footnotetext{
* Corresponding author: j.gajewski@pollub.pl
} 
between the two elements we are dealing with total endoprosthesis. We also distinguish endoprosthesis primary and revision. The primary one occurs when we deal for the first time with such an operation. Reviewing endoprosthesis occurs when we replace part or all of the aforementioned joint with a new one. This situation can take place if the current prosthesis has loosened, become infected, moves, causes pain or bone damage. Indications for joint replacement surgery are: pain, old injuries, axial deformation of the lower limb, limitation of daily activities or advanced degeneration of the joint. Unfortunately, there are also contraindications for the procedure and these are: young age of the patient, infections of the joint and surrounding tissues, osteoporosis, extensive varicose veins, thromboembolism or very major limb deformation. Time returning to full efficiency after the surgery is usually a period of about 3 months [3-5].

\section{Materials used in arthroplasty}

For the first time alloplastic surgery was done by Dr. Themistokles Gluck in the 80 s of the 19th century. He replaced 14 joints, and the implants were hand-made of ivory by doctor. Later, the implants were made of biologically neutral steel, which consisted mainly of cobalt, chromium, vanadium, and titanium which was introduced over the years. These materials began to be coated with hydroxyapatite to better integrate with the human bone. The latest discovery is tantalum, the structure of which is very similar to bone structure, which is why the bone exceeds that of well-known materials and gives good fixing of the prosthesis. However, there is a certain obstacle in the widespread use in prosthetics, namely the high price [6]. It is important that the prosthesis is made of a material that has properties similar to bone properties, e.g. elasticity factor. In order to maintain and stabilise the endoprosthesis, three types of fixings are used in the right place. The first of them is cement fastening. In this fixation bone adhesive is used, which is commonly called cement. Bone adhesive is a medical material that fills the space between the endoprosthesis and the bone. It is also designed to transfer loads and stabilise the prosthesis. Its most important features are biocompatibility, that is, compatibility with human tissue and bioactivity, or the ability to connect to the bone. The most commonly used types of cement are: polymer cement, ceramic phosphate-calcium, composite and hydrogel. The second fixation is cementless, which is based on the fact that the tissue grows into the implant. The third fixation is a hybrid attachment consisting in the fact that the femoral part is fixed without cement, whereas the tibial bone is cemented. [7-9]. This material must exhibit biotolerance and biocompatibility, i.e. not cause acute or chronic body reactions. Its properties have to fit into a certain set of properties such as: high strength, adequate abrasion resistance and stress corrosion, adequate ductility, hardness and low density of the implant, no tendency to form clots and appropriate electrical properties. Generally, biomaterials intended for prostheses can be divided into metallic and non-metallic. The group of metals includes: cobalt alloys, titanium and its alloys, and shape memory alloys. On the other hand, the group of non-metallic materials includes: ceramic, polymer, carbon and composite materials [10].

\section{The design of the endoprosthesis of the knee joint}

\subsection{CT scan processing}

In the design of artificial joints, it is very important to reproduce the anatomical shape of the patient's bone as faithfully as possible. That is why the first stage was the CT scan processing, consisting in the processing of $2 \mathrm{~d}$ data into the $3 \mathrm{~d}$ model $[11,12]$. The Mimics Research 20.0 program was used to properly prepare the bone model for the prosthesis model. It is a package that is used to process data into an image, e.g.: computed tomography (CT), magnetic resonance imaging (MRI) or confocal microscopy, and obtaining 3D models by means of image segmentation [13-17]. These models are later used in various engineering applications. This program is used in various branches of the medical industry, such as: pulmonology, orthopaedics or facial-jaw surgery. The first step is to download the received CT scan in the DICOM input format. The program presents the downloaded scan in the front, top, side and view set by the user. We can hide or show: the coordinate system, the plane relative to the coordinate system or the muscle and skin system (Fig. 2). On the right side there are four windows that refer to: $2 \mathrm{D}$ data or the mask, generated 3D object, measurements and FEM grid, and charts generated on the basis of operations performed on a given model.

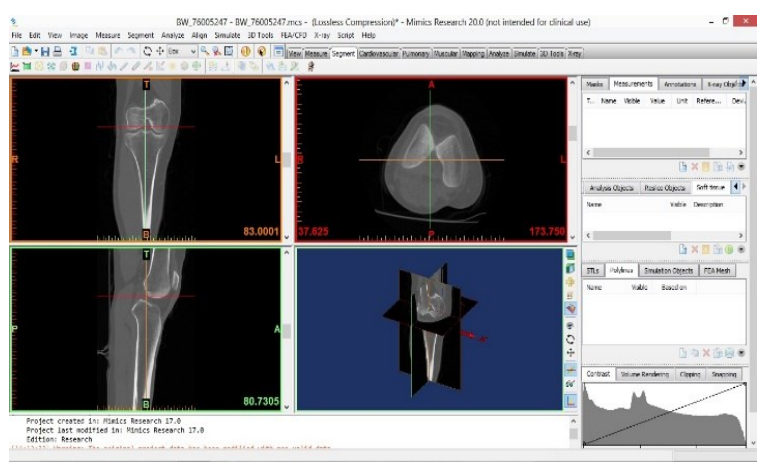

Fig. 2. The Mimics Research 20.0 interface.

The next step is to conduct a process called thresholding, which involves obtaining a binary image by setting a brightness threshold. Pixels that are lighter than the designated threshold gain one value and darker ones get the second. The aim of this process is to highlight the foreground elements. Next, we need to transform the extracted data from 2D images into a 3D model using the Calculate Part from Mask function. However, sometimes there is a need for improvement, the so-called masks, or bone images, from which the 3D model will be created. To do this, we use the Calculate Polylines from Part function. This tool will create polylines that will later be filled with the Cavity Fill from Polylines tool. After proper preparation of the mask and the creation of the 3D model, you can notice many osteolytic outbreak (so-called cheese holes), which indicate cartilage wear and the need 
for alloplastic surgery. The final model obtained in Mimics Research 20.0 is shown in Figure 3.

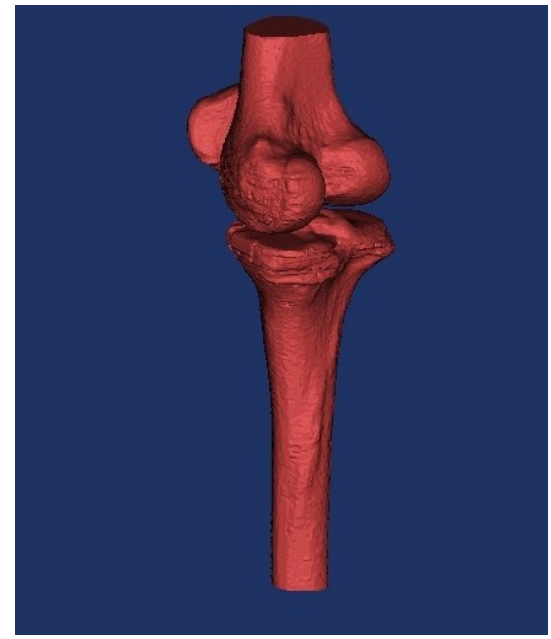

Fig. 3. Generated 3D bone model.

\subsection{The design of the constructed prosthesis}

The design of the endoprosthesis is based on the following assumptions and simplifications [18-21]:

- modelling only fragments of bones needed to construct the prosthesis,

- bone model reflects only their general shape, not anatomical details,

- lack of recognition of individual bone tissues,

- selection of the appropriate shape and material of the individual parts of the prosthesis.

The designed endoprosthesis will consist of four elements: the kneecap, the femoral part, the tibial part and the tibial bearing insert. Each of these elements has been designed based on the actual dimensions of the obtained 3D bone model. The basic fixing of all fragments of the endoprosthesis will be cement. They have been individually matched to each element: cutting planes, mounting method and material.

Materials used in the design process:

- kneecap - a porous ceramic biomaterial, i.e. a ceramic glazed material.

- femoral part and tibia-titanium $\beta$-Ti3Au alloy

- tibial bearing insert - UHMWPE polyethylene reinforced with a metal net of stainless steel.

The design process began with bone dimensioning. The next step was to cut the used cartilage and start the modelling process on the obtained planes. Three of the four elements of the endoprosthesis were designed on its basis. The first element designed was the tibial part equipped with a tibial plate on the pin and brackets and a facilitating canal for possible reconstruction of the ligaments. Height had to be chosen so that the height of healed tibia cartilage was combined with the total height of the tibia part and the tibial bearing insert. The next projected element was the femoral part. It is the largest part of the endoprosthesis and therefore it was additionally equipped with bolts for better fixing. After mapping the general shape, it was necessary to remove the excess material, give a proper shape to the condyles and to round the external outline of the prosthesis. The element that was designed on the basis of the tibial and femoral part was a tibial bearing insert. It will be pressed into the tibial part. The outer dimension of the contour of the underside of the tibial bearing insert corresponds to the internal dimension of the contour of the upper part of the tibial part. The upper part of the insert has been modelled on the basis of the condyles of the femoral part, which must be able to lie in it and move without difficulty. The last projected part was the kneecap (Fig. 4).

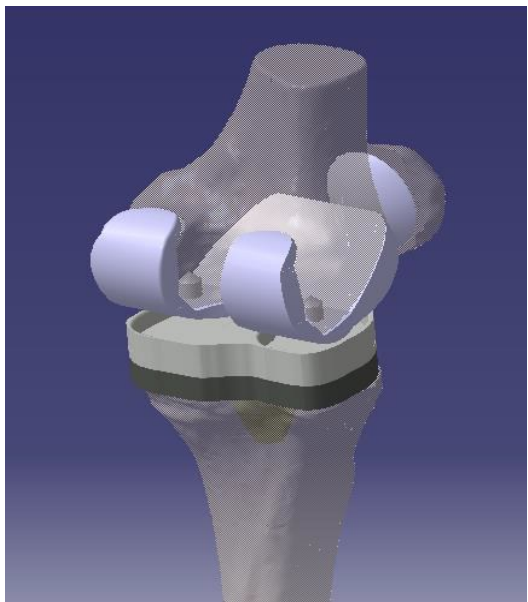

Fig. 4. 3d model of the endoprosthesis in the assembly.

\section{Strength analysis}

\subsection{FEM method}

Strength analysis was carried out using the Finite Element Method. It is an advanced method of solving systems of differential equations, based on the division of the domain or discretisation into finite elements, for which the solution is approximated by specific functions, and performing actual calculations only for nodes of this division [22-28]. By means of this method, the structural strength of the structure is tested in the computer mechanics, it simulates strains, stresses or displacements. Dynamics, kinematics and statics of machines are also examined.

\subsection{Strength analysis and its stages}

Strength analysis was performed in program Abaqus 16.3 on: femoral part (Fig. 5, Fig. 6), tibial bone (Fig. 7, Fig. 8) and tibial bearing insert (Fig. 9, Fig. 10). After importing the models, material properties were assigned.

Table 1. Properties of materials used for analysis.

\begin{tabular}{|l|l|l|l|}
\hline Element & Material & $\begin{array}{l}\text { Young's } \\
\text { Modulus } \\
{[\mathrm{MPa}]}\end{array}$ & $\begin{array}{l}\text { Poisson's } \\
\text { ratio [-] }\end{array}$ \\
\hline Tibial part & $\begin{array}{l}\text { titanium } \beta- \\
\text { Ti3Au alloy }\end{array}$ & 188380 & 0.3 \\
\hline Femoral part & $\begin{array}{l}\text { titanium } \beta- \\
\text { Ti3Au alloy }\end{array}$ & 188380 & 0.3 \\
\hline $\begin{array}{l}\text { Tibial } \\
\text { bearing } \\
\text { insert }\end{array}$ & $\begin{array}{l}\text { UHMWPE } \\
\text { polyethylene } \\
\text { reinforced with } \\
\text { a metal net of } \\
\text { stainless steel }\end{array}$ & 894 & 0.41 \\
\hline
\end{tabular}


The load should be applied evenly, therefore the applied load type is pressure, for the application of which we need the surface of the analysed part and the pressure force. The strength is obtained from the weight of the person for whom the prosthesis was designed (1). We accept three theoretical masses, that is: $60 \mathrm{~kg}, 80 \mathrm{~kg}$ and $100 \mathrm{~kg}$. (2). We break each of the pressure forces into two cases according to the Maquet's model, that is, we calculate $42.5 \%$ and $93 \%$ of the given mass (Table 6.1 ).

$$
\begin{gathered}
\mathrm{F}=\mathrm{m} * \mathrm{~g}=60 \mathrm{~kg} * 9,81 \mathrm{~ms} 2=589 \mathrm{~N} \\
\mathrm{P}=\mathrm{F} * \mathrm{~S}=589 \mathrm{~N} 720 \mathrm{~mm} 2=0,81 \mathrm{MPa}
\end{gathered}
$$

The elements being analysed are elements with complex geometry, therefore the Tet type C3D10 mesh was imposed on the model.

\subsection{Results}

Strength analyses allowed to obtain maps of distribution of stresses and displacements in the elements of the endoprosthesis, presented below.

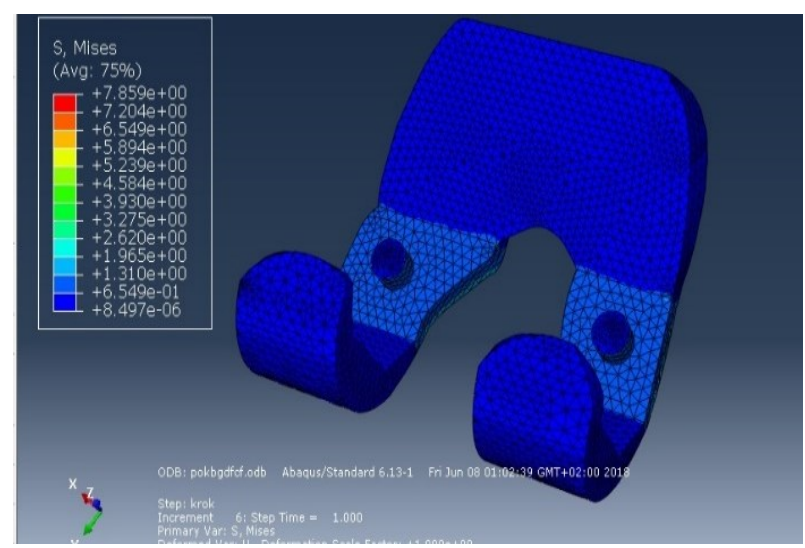

Fig. 5. Distribution of von Mises stresses in the femur.

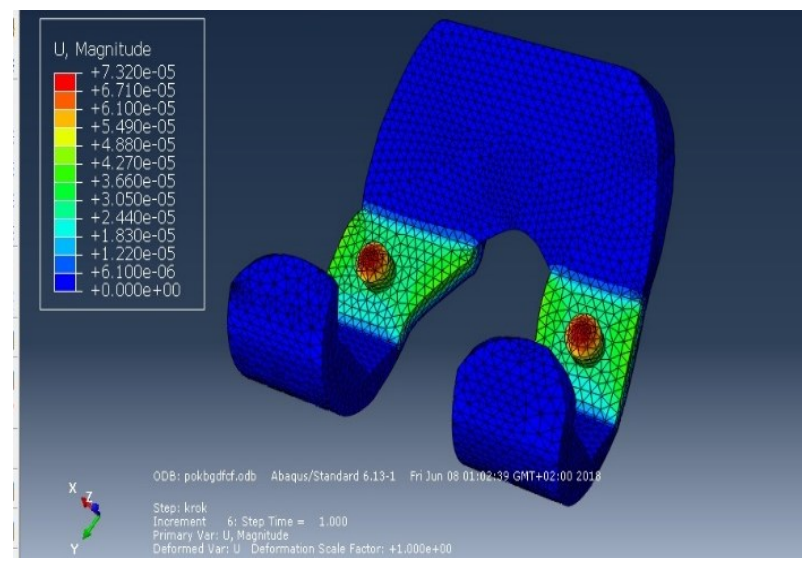

Fig. 6. Distribution of dislocations in the femur.

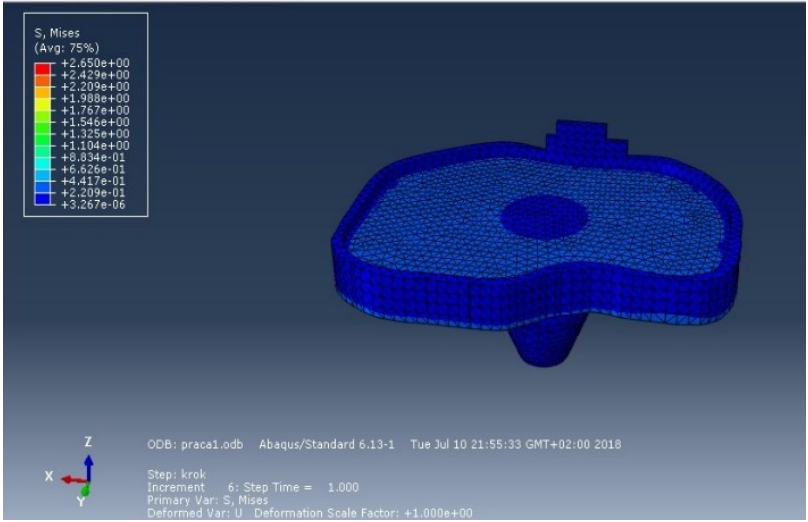

Fig. 7. Distribution of von Mises stresses in the tibial part.

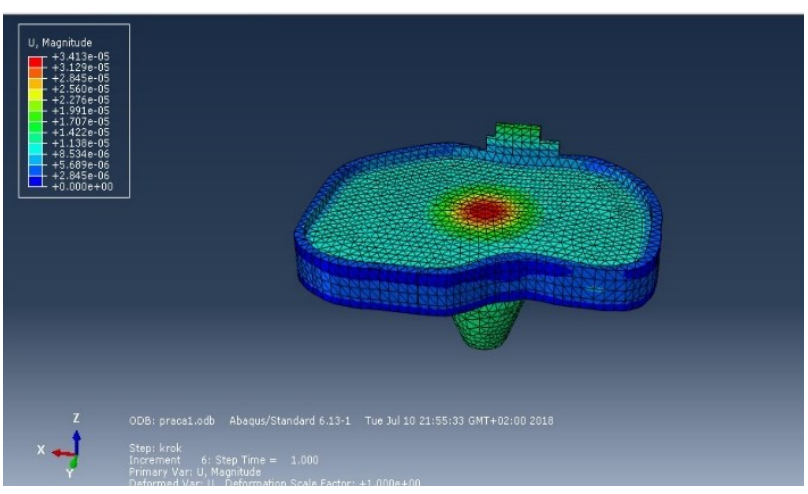

Fig. 8. Distribution of dislocations in the tibial part.

The tibial and femoral parts were made of the same material. Both elements will transfer the given load. Slightly greater displacements and stresses occur in the femur. Occurring displacements are on the level of 10-5 $\mathrm{mm}$. Stresses do not exceed $8 \mathrm{MPa}$. In the femoral part, the greatest stresses occur in the bolts, but also in the plane in which the greatest pressure will be exerted. In the tibial part, the greatest stresses occur on the upper surface and around the perforated hole in the event of a possible need to reconstruct the ligament.

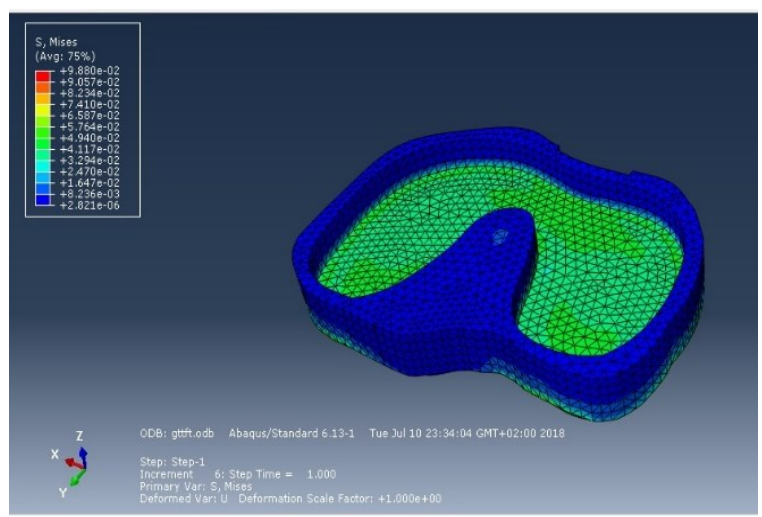

Fig. 9. Distribution of von Mises stresses in the tibial bearing insert. 


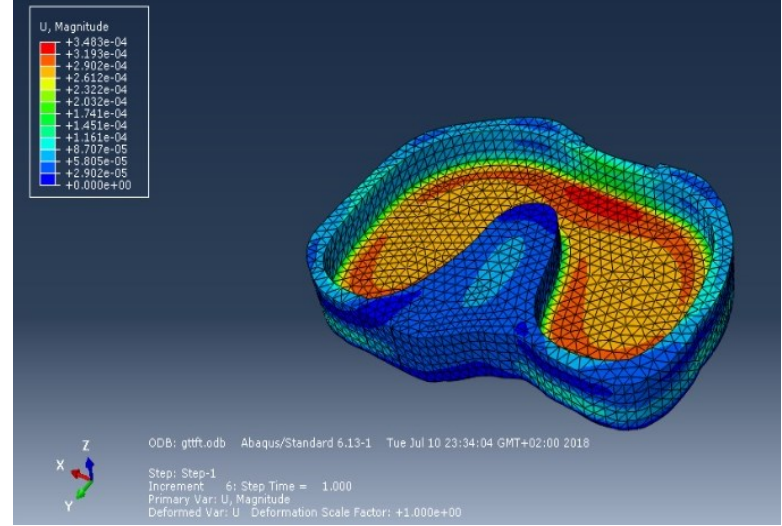

Fig. 10. Distribution of dislocations in the tibial bearing insert.

The greatest stress and displacement of all parts of the prothesis occurs in the tibial bearing insert. It is affected by its position between the tibial part in which it is pressed and the femoral part that exerts pressure. The insert is made of polyethylene whose Young's modulus is much lower than in the case of the femoral or tibial part. The highest values of stresses and displacements can be seen on the lower surface, i.e. the contact surface with the tibial part and on the upper surface or the contact surface with the femoral part.

\section{3D printing}

3D printers have probably moved to the forefront of the medical revolution. They print limb prostheses, blood vessels, teeth, jaws, parts of bones and skulls. Increasingly, we hear about experiments with the printing of tissue from living cells. Materials used in printing can be divided into materials: plastic (ABS, PLA, PVA, PC), metal (cobalt, chrome, titanium), resin (transparent resin), glass (TGlase), rubber-like (NinjaFlex), wood-like (LayWood) and other (chocolate, live cells) . More and more often, new, innovative method of printing from living tissues is being introduced. It involves taking stem cells of the patient, which then they should multiply in the laboratory. They are loaded into the toner creating a biotouch then. This goes to the printer, which then alternately prints the layers of cells based on the "scaffolding" of synthetic gel or collagen. When all of it will be printed, the tissue allows you to mature and then removes the hydrogel. In this way, prostheses created from the natural tissues of the patient iris [28]. The printing techniques are: SLA, SLS, SLM, FFF/FDM, selective bonding and lamination. The most commonly used method is the FFF/FDM method. This printing consists in heating the plastic, which is supplied in the form of a vein to the print head. Then the material is brought to semi-liquid state. Layers are applied in the XY axis, and after this operation is completed, the head is lifted up or down the table and the next layer is applied. The warmed-up material is bonded under the influence of high temperature and quickly solidifies to form a uniform structure. 3D printing is a brilliant invention to visualise and better understand many mechanisms. There are many educational benefits from it, such as: developing the imagination, better perception of the $3 \mathrm{~d}$ model, learning about many new materials. $3 \mathrm{D}$ printing gives us a physical model that we can touch, fold, unfold. With this opportunity, the education of young doctors will be more effective. Then they can plan the treatment much better and prepare for it. It is also a help for patients who will be presented on the $3 \mathrm{~d}$ surgery course model. This is much clearer than just verbal explanation [28].

\section{Conclusion}

Continuous development of arthroplasty is a field for doctors and engineers to get better and better. Individual prosthesis fitting results in the accurate preparation of the alloplastic procedure, the shortening of rehabilitation time and the prolongation of the prosthesis use time. The strength analyses carried out ensure that the designed prosthesis model is appropriate for a given patient, will withstand the given load and will not lose structural integrity. The possibility of $3 \mathrm{~d}$ printing allows for a better visualization of the model and checking in reality how it works and whether no corrections are required. Continuous development on the material level allows you to obtain more and more new materials that show better tolerance, compatibility and conformity. Newer methods of removing used cartilage are used to reduce postoperative pain and rehabilitation time. All these treatments are aimed to improving the quality of life of patients requiring knee replacement by combining medicine, bioengineering and material engineering.

\section{References}

1. D. Tejszerska, E. Świtoński, M. Gzik, A. Głowacka, Biomechanika narząu ruchu czlowieka: praca zbiorowa (Katedra Mechaniki Stosowanej, Wydział Mech-Technol, Politechnika Śląska; Wydawnictwo Naukowe Instytutu Technologii Eksploatacji - PIB, Gliwice; Radom, 2011) (in polish)

2. How Your Knee Works | Articles | Mount Nittany Health System, (available at https://www.mountnittany.org/articles/healthsheets/ 4043)

3. J. Zubrzycki, R. Karpiński, B. Górniak, Applied Computer Science 12 (2016) (available at http://yadda.icm.edu.pl/yadda/element/bwmeta1.ele ment.baztech-69507fc1-0eca-4b84-b42a0c1edb67506c)

4. Endoproteza kolana (endoproteza stawu kolanowego) - Kraków - rodzaje endoprotez, operacje | Sport-Med Kraków, (available at http://www.sport-med.pl/leczenie/endoprotezakolana) (in polish)

5. J. Zubrzycki, N. Smidova, Applied Mechanics and Materials 613, 172-181 (2014)

6. A. Laska, Biomaterials used in tissue engineering for tissue regeneration (2017) (available at https://depot.ceon.pl/handle/123456789/12136)

7. J. Caban, R. Karpinski, D. Barta, (IEEE, 2018; https://ieeexplore.ieee.org/document/8373322/), pp. $1-7$ 
8. A. Balin, Cementy $w$ chirurgii kostnej (Wydawnictwo Politechniki Śląskiej, Gliwice, 2016) (in polish)

9. H. Lelovics, T. Liptakova, Acta Bioeng. Biomech. 12, 63-67 (2010)

10. L. A. Dobrzański, Materiały inżynierskie $i$ projektowanie materiałowe: podstawy nauki o materiałach $i$ metaloznawstwo (Wydawnictwa Naukowo-Techniczne, Warszawa, 2006) (in polish)

11. M. McGurk, A. A. Amis, P. Potamianos, N. M. Goodger, Ann R Coll Surg Engl. 79, 169-174 (1997)

12. J. Guarino, S. Tennyson, G. McCain, L. Bond, K. Shea, H. King, J Pediatr Orthop. 27, 955-960 (2007)

13. M. Frame, J. S. Huntley, The Scientific World Journal 2012, 1-7 (2012)

14. K. Torres, G. Staśkiewicz, M. Śnieżyński, A. Drop, R. Maciejewski, Folia Morphol. (Warsz). 70, 1-4 (2011)

15. V. Bagaria, S. Deshpande, D. D. Rasalkar, A. Kuthe, B. K. Paunipagar, Eur J Radiol. 80, 814-820 (2011)

16. Model bryłowy ze skanów CT (tomografia komputerowa) - techtutor.pl, (available at http://techtutor.pl/model-brylowy-ze-skanow-ct/) (in polish)

17. R. Karpiński, J. Jonak, J. Maksymiuk, Applied Computer Science, 84-93 (2018)
18. K.-T. Kang, J. Son, S. K. Kwon, O.-R. Kwon, J.-H. Park, Y.-G. Koh, Composite Structures. 201, 141150 (2018)

19. T. F. Grieco, A. Sharma, R. D. Komistek, H. E. Cates, The Journal of Arthroplasty. 31, 694-701 (2016)

20. B. Innocenti, J. Bellemans, F. Catani, The Journal of Arthroplasty. 31, 295-301 (2016)

21. K.-T. Kang, Y.-G. Koh, J. Son, O.-R. Kwon, J.-S. Lee, S.-K. Kwon, The Journal of Arthroplasty 33, 572-579 (2018)

22. J. Gajewski, P. Golewski, T. Sadowski, Compos. Struct. 159, 589-599 (2017)

23. J. Gajewski, J. Podgórski, J. Jonak, Z. Szkudlarek, Computational Materials Science 43, 115-118 (2008)

24. J. Gajewski, T. Sadowski, Computational Materials Science. 82, 114-117 (2014)

25. K. Falkowicz, H. Debski, A. Teter, AIP Conference Proceedings 1922, 080004 (2018)

26. K. Falkowicz, Archives of Civil Engineering. 63(4), 161-172 (2017)

27. P. Rozylo, H. Debski, P. Wysmulski, K. Falkowicz, Compos Struct. 204, 2017-216 (2018)

28. Medycyna i druk 3D, (available at https://mlodytechnik.pl/technika/28781-medycyna-idruk-3d) (in polish) 